\title{
choer
}

\section{Percepção de valor de assinantes de cursos on-line em economia criativa}

\section{Francisca Angélica de Oliveira}

Head de Educação na Plataforma Asta

Especialista em Pesquisa de Comportamento e Consumo

angelicaoliveiralab@gmail.com

[https://orcid.org/

0000-0002-8400-2155

\author{
Daniel Mill \\ Professor na Universidade Federal de São Carlos - UFSCar \\ Membro do Grupo Horizonte \\ mill@ufscar.br \\ [https://orcid.org/ \\ 0000-0002-8336-3645
}

\section{Resumo}

\begin{abstract}
Este artigo investiga a percepção de valor dos assinantes de cursos on-line em economia criativa. Para tanto, os objetivos principais do estudo englobavam conhecer a persona dos assinantes, mapeá-los em pelo menos 3 plataformas de cursos e analisar a percepção dos usuários, compilando os dados coletados na ferramenta "Mapa de Empatia". Trata-se de pesquisa qualitativa realizada por meio de questionário on-line com 100 respostas válidas, distribuídas em 3 grandes eixos: a) persona dos assinantes de cursos; b) experiência de uso das plataformas de cursos; e c) experiência de aprendizagem nas plataformas de cursos. A fundamentação teórica teve por base materiais didáticos sobre os macrotemas: a) gestão estratégica da educação a distância (EaD); b) gestão de negócios em educação e tecnologia; e c) inovação, empreendedorismo digital e startups na área de educação. Os resultados demonstram que a persona mapeada é mulher, tem cerca de 40 anos de idade, pertence à classe C, possui Ensino Superior completo e é empreendedora no setor da economia criativa. Sua percepção de valor ao assinar determinada plataforma de cursos passa por um processo de escolha entre aquelas que viabilizem um processo de aprendizagem considerado fluido e criativo.
\end{abstract}

Palavras-chave gestão estratégica da educação a distância; startup educacional; curso online aberto e massivo; gestão de negócios em educação e tecnologia; economia criativa.

\footnotetext{
Conhecer: debate entre o público e o privado

2021, Vol. 11, no 27

ISSN 2238-0426

DOI https://doi.org/10.32335/2238-0426.2021.11.27.7156

Licença Creative Commons Atribuição (CC BY 4.0)

Data de submissão 10 mai 2021

Data de publicação 28 ago 2021
} 


\title{
Subscribers' perceived value of online courses in creative economy
}

\begin{abstract}
This article investigates the subscribers' perceived value of online courses in creative economy. To do this, the main objectives of the study encompassed knowing the subscribers' persona, mapping them on at least 3 course platforms, and analyzing the users' perception, by gathering the data collected in the tool "Empathy Map." This is a qualitative research carried out by means of an online questionnaire containing 100 valid answers, distributed on 3 main axes: a) course subscribers' persona; b) experience in using course platforms; and c) learning experience on course platforms. The theoretical framework has been based upon teaching materials on the macro-themes: a) strategic management in distance education (DE); b) business management in education and technology; and c) innovation, digital entrepreneurship and startups in the education industry. The results show that the persona mapped is a woman, is about 40 years old, belongs to class $C$, has completed Higher Education, and is an entrepreneur in the creative economy sector. Her/his perceived value in subscribing to a certain course platform goes through a process of choosing between those that enable a learning process regarded as fluid and creative.
\end{abstract}

Key words strategic management in distance education; educational startup; massive open online course; business management in education and technology; creative economy.

\section{Percepción de valor de suscriptores de cursos en línea en economía creativa}

\section{Resumen}

Este artículo investiga la percepción de valor de suscriptores de cursos en línea en economía creativa. Para ello, los principales objetivos del estudio abarcaron conocer la persona de los suscriptores, mapearlos en al menos 3 plataformas de cursos y analizar la percepción de los usuarios, mediante la recopilación de los datos recogidos en la herramienta "Mapa de Empatía". Se trata de una investigación cualitativa realizada mediante un cuestionario en línea que contiene 100 respuestas válidas, distribuidas en 3 ejes principales: a) persona de los suscriptores de cursos; b) experiencia en el uso de plataformas de cursos; y c) experiencia de aprendizaje en plataformas de cursos. El marco teórico se ha basado en materiales didácticos sobre los macrotemas: a) gestión estratégica de educación a distancia (EaD); b) gestión empresarial en educación y tecnología; y c) innovación, emprendimiento digital y startups en la industria de la educación. Los resultados muestran que la persona mapeada es mujer, tiene alrededor de 40 años, pertenece a la clase $C$, ha completado la educación superior y es emprendedora en el sector de la economía creativa. Su percepción de valor al suscribirse a una determinada plataforma de cursos pasa por un proceso de elección entre aquellas que permiten un proceso de aprendizaje considerado fluido y creativo.

Palabras clave gestión estratégica de educación a distancia; startup educativa; curso en línea masivo abierto; gestión empresarial en educación y tecnología; economía creativa. 


\section{Perception de valeur par les abonnés des cours en ligne sur l'économie créative}

\section{Résumé}

Cet article étudie la perception de valeur par les abonnés des cours en ligne sur l'économie créative. Pour ce faire, les principaux objectifs de l'étude comprenaient la connaissance de la persona des abonnés, leur cartographie sur au moins 3 plateformes de cours et l'analyse de la perception des utilisateurs, rassemblant les données collectées dans l'outil « Carte d'Empathie ». II s'agit d'une recherche qualitative réalisée au travers d'un questionnaire en ligne qui contient 100 réponses valides, réparties en 3 axes principaux: a) persona des abonnés au cours; b) expérience dans l'utilisation des plateformes de cours; et c) expérience d'apprentissage sur des plateformes de cours. Le cadre théorique a été basé sur des supports pédagogiques sur les macrothèmes: a) gestion stratégique de l'enseignement à distance (EaD); b) gestion d'entreprise dans l'éducation et la technologie; et c) innovation, entrepreneuriat numérique et startups dans le secteur de l'éducation. Les résultats montrent que la persona cartographié est une femme, a environ 40 ans, appartient à la classe C, a terminé des études supérieures, et est une entrepreneure dans le secteur de l'économie créative. Sa perception de valeur lors de la souscription à une certaine plateforme de cours passe par un processus de choix entre celles qui permettent un processus d'apprentissage considéré comme fluide et créatif.

Mots-clés gestion stratégique de l'enseignement à distance; startup éducative; cours en ligne ouvert et massif; gestion d'entreprise dans l'éducation et la technologie; économie créative.

\section{Introdução}

Este artigo tem como objetivo geral identificar as motivações envolvidas no processo de tomada de decisão do usuário de plataformas de ensino no formato curso online aberto e massivo (massive open online course $[\mathrm{MOOC}]$ ) ao optar por pagar por determinado produto educacional, com conteúdos especificamente do setor de economia criativa. Os objetivos específicos são: a) conhecer a persona dos assinantes de cursos de economia criativa no formato MOOC; b) mapear assinantes de pelo menos 3 plataformas diferentes; e c) analisar a percepção da proposta de valor ao optar por assinar determinado produto educacional/curso, compilando-a em um "Mapa de Empatia".

As principais hipóteses do estudo que envolvem as motivações dos usuários ao investirem financeiramente em produtos educacionais da economia criativa no formato MOOC eram: a) o fato de encontrarem flexibilidade nesse formato de ensino; b) a relação custo-benefício ainda é mais atraente em comparação aos cursos presenciais; c) a possibilidade de obter um certificado gera uma ideia de credibilidade; d) a instituição que promove o curso credita confiança o suficiente em sua comunicação de marca, dentre outras. O texto pode contribuir para pensar a gestão estratégica da educação a distância $(E a D)$ - com foco na gestão de negócios em educação -, tendo como base o acesso ao conhecimento sobre os principais hábitos de comportamento e consumo dos assinantes de conteúdos da economia criativa em formato MOOC hospedados em plataformas 
educacionais. Os resultados podem ser adotados por outros pesquisadores, especificamente interessados em temáticas relacionadas com as motivações e a percepção de propostas de valor por parte do público diante de determinado produto educacional.

As motivações do usuário ao assinar plataformas de ensino passam, necessariamente, pela importância desse tema sob o viés da gestão estratégica da EaD que, segundo Mill (2017, p. 4): "guarda para si diversas especificidades que exigem e promovem um tipo de gestão muito diferente da gestão de outras atividades. Pode-se dizer que a profissionalização da gestão de EaD parece ainda emergente e necessária”. Desse modo, o gestor de EaD precisa ter uma visão macro de cenários para conseguir gerar inovações em nível micro. Além de estar atento aos diversos sistemas (e seus subsistemas) que envolvem a complexidade dessa tarefa, o profissional precisa observar os movimentos que compõem todo um cenário social que afeta os usuários de seus produtos/serviços e suas consequentes absorções de aprendizado e percepção de valor da entrega de tais conteúdos.

É possível encontrar semelhanças com a bibliografia de Araújo (2020) quando se discorre sobre a importância de pensar a gestão de negócios em educação e tecnologias, de modo integrado. Tal como o gestor estratégico de determinado sistema de EaD, as habilidades de um gestor de negócios nesse setor também envolvem orquestrar estruturas organizacionais, contemplando aspectos como marketing, gestão de pessoas, produção e financeiro, planejamento estratégico e gestão da informação. Ademais, em ambos os casos, o empreendedorismo e a capacidade de planejar negócios são habilidades desejáveis, visto que seus respectivos sistemas demandam inovações constantes. Um curso na modalidade $\mathrm{EaD}$, ainda que alojado no seio de uma instituição mantenedora tradicional, não difere muito em termos de habilidades exigidas na gestão de negócios em educação e tecnologias quanto à série de exigências relativas a performance, resultados e medição de impactos. Em ambos os casos existe um sistema complexo a ser gerenciado, mensurado e avaliado, onde:

Independentemente do tipo de negócio, se ele é mais tradicional ou se é uma startup, e indiferente da área do negócio, se é uma prestação de serviços ou uma indústria, a gestão de negócios deve estar presente para fazer a diferença entre o sucesso e o fracasso (Araújo, 2020, p. 6).

Portanto, este estudo se justifica pela conexão entre esses dois macroassuntos: a) gestão estratégica da $\mathrm{EaD}$; e b) gestão de negócios em educação e tecnologias, tendo como viés o estudo da persona que investe financeiramente em determinado produto/ serviço educacional tecnológico no setor de economia criativa. Ao aplicar os conceitos de gestão estratégica da EaD em produtos e serviços no universo das startups educacionais 
ou de cunho empresarial, essa profissionalização do gestor, além de emergente e necessária, torna-se obrigatória para que o modelo de negócio consiga prosperar. O que se tem percebido com o crescimento do número de startups educacionais no Brasil é que tais formas de transmissão (e consequente lucratividade) de conteúdos digitalizados têm assumido vieses cada vez mais criativos e competitivos, entregando diferentes propostas de valor aos usuários. É exatamente nesse momento que a gestão estratégica da EaD se torna fundamental, ao adaptar os processos e as metodologias já usados(as) em negócios educacionais tradicionais para a linguagem das startups, de modo a entregar a mesma qualidade e eficiência no processo de ensino-aprendizagem. Domingues, Floyd-Wheeler e Nascimento (2017, p. 1) abordam que esse movimento se configura como uma nova realidade brasileira na qual, com a ascensão do acesso aos dispositivos móveis por parte dos consumidores, criam-se "novas relações de negócios em atividades tradicionais como a educação ou outras atividades do terceiro setor".

Nesse contexto, os resultados parciais da pesquisa demonstram que os usuários de plataformas de cursos no setor de economia criativa, hospedadas no formato MOOC, apresentam uma persona que sempre busca inovações nas maneiras de acessar e consumir tais conteúdos, além de não serem fidelizados por nenhuma plataforma específica e aplicarem o conhecimento adquirido majoritariamente em suas vidas pessoais e profissionais, em proporções praticamente iguais. Apresentam-se a seguir os tópicos: a) metodologia (etapas da pesquisa, instrumentos e locais de coleta de dados); b) resultados (análise dos dados coletados da pesquisa, divididos em 3 seções: persona dos assinantes de cursos do setor de economia criativa no formato $\mathrm{MOOC}$ e como foram suas respectivas experiências de uso e de aprendizagem nas plataformas); e c) conclusão (resumo conceitual de todos esses dados em um Mapa de Empatia, seguido de análises sobre a gestão estratégica da EaD e a importância de inovar em seus sistemas).

\section{Metodologia}

Este artigo adotou a pesquisa qualitativa como metodologia da ferramenta Google Forms, que foi lançada em grupos específicos nas redes sociais onde se encontram os assinantes do segmento de cursos investigados. Os dados coletados na pesquisa qualitativa foram compilados no Mapa de Empatia que, segundo o Serviço Brasileiro de Apoio às Micro e Pequenas Empresas (Sebrae, 2020a), é "uma ferramenta simples e visual usada para descobertas sobre usuários. É eficiente para entender a audiência de produtos e serviços, tanto dos clientes quanto de concorrentes". Quando usadas de modos complementares, essas 2 ferramentas demonstram grandes potencialidades de captação de percepção de valor do usuário, exatamente pelo fato de aprofundarem-se em outros aspectos que 
consideram nuances socioculturais de comportamento e consumo. O processo desta pesquisa se dividiu em 3 macrotarefas, distribuídas em um plano de ação, intituladas: a) antes; b) durante; e c) depois.

A etapa "antes" caracterizou-se, basicamente, pela preparação das ferramentas e pelos fundamentos da pesquisa. Desse modo:

- Realizou-se um estudo prévio do tema por meio de validação com as chief executive officers (CEOs) da Rede Asta e da análise da viabilidade de aplicação dos resultados da pesquisa no planejamento estratégico 2021 da empresa;

- Referências bibliográficas foram buscadas na plataforma Mendeley e os demais arquivos acadêmicos foram adquiridos oportunamente pelos autores;

- Procedeu-se à análise do modelo de negócios e benchmarking das principais plataformas no formato MOOC concorrentes da Plataforma Asta;

- As 5 principais plataformas para prospecção de respostas dos usuários foram eleitas;

- Os textos foram fichados e um quadro foi elaborado para estruturar a revisão bibliográfica (selecionando as principais referências com vistas à melhor distribuição entre as 2 grandes áreas da pesquisa - gestão estratégica da EaD; e b) gestão de negócios em educação e tecnologias -, com foco na percepção de valor do usuário das plataformas no formato MOOC;

- Elaborou-se a redação de um texto final sobre a literatura abordada (revisão bibliográfica da metodologia de pesquisa); e

- Por fim, também foram elaborados os instrumentos de coleta de dados e aprovou-se um cronograma para a aprovação da pesquisa no conselho de ética da Rede Asta.

Já na etapa "durante":

- Os instrumentos de coleta de dados foram aplicados e posteriormente analisados, usando gráficos gerados pelo próprio Google Forms, nuvens de palavras do Pro Word Cloud (suplemento do pacote MS Office);

- O Mapa de Empatia foi elaborado primeiro no Canvas do Serviço Brasileiro de Apoio às Micro e Pequenas Empresas (Sebrae) e depois no template do Google Drawings (disponibilizado pelo blog Canvas Brasil); e

- Ao final, elaborou-se o relatório desta pesquisa no aplicativo "Apresentações", do Google Docs.

A pesquisa foi enviada por meio de um link da ferramenta Google Forms, sendo composta por 24 perguntas, divididas em 3 seções principais: a) perfil do respondente; b) experiência do respondente com o uso da plataforma no formato MOOC na qual investiu financeiramente em um curso de economia criativa; e c) sua experiência geral de aprendizagem do respondente em cursos on-line. Dentre essas 24 questões, 10 eram abertas e 14 eram de múltipla escolha - 7 permitiram a marcação de mais de 1 item nas seções 2 e 3 (experiências de uso e de aprendizagem, respectivamente). O formulário foi divulgado em 
diversos meios digitais, como: a) grupo no Facebook "Eduk | Artesanato"; b) redes sociais dos pesquisadores, (WhatsApp, LinkedIn, Facebook e Instagram etc.); e c) divulgação na Plataforma Asta, por meio de post no feed e envio por e-mail para sua base de 5 mil usuários cadastrados. O questionário tinha um tempo médio de 10 minutos para preenchimento e ficou aberto para respostas durante o período de 2 meses, obtendo 104 respostas no total, sendo 96\% desses respondentes assinantes de pelo menos 1 das 5 maiores plataformas identificadas no objeto da pesquisa (Eduk, Domestika, Udemy, Coursera e Descola). Dentre esses respondentes, obtiveram-se 4 respostas que foram excluídas para fins de análise real nesta pesquisa, pelo fato dos usuários responderem "nunca ter investido financeiramente em um produto educacional” ou afins. Desse modo, 100 respostas foram consideradas na fase de apresentação de resultados desta pesquisa.

Por fim, na etapa "depois" foram prospectados diversos congressos, publicações e eventos acadêmicos nas áreas Educação, Economia Criativa e Negócios de Impacto Social onde esta pesquisa possa vir a ser divulgada. Também se estruturou um relatório da pesquisa para sua posterior aplicação no treinamento da nova equipe da Plataforma Asta e no planejamento estratégico de 2021 da Rede Asta, que é um negócio social atuante na economia do tipo "feito a mão", levando artesãs a se tornarem empreendedoras. Na definição de Yunus (2018 como citado em Limeira, 2018, p. 2), "o negócio social é uma empresa que não envolve perdas e não paga dividendos, inteiramente dedicada à realização do propósito social”. Há 15 anos no setor do artesanato, sempre tendo como ponto principal a geração de renda, conhecimento e rede para as artesãs envolvidas, a Asta já experimentou diferentes modelos de negócios e lançou, em 2018, seu primeiro produto digital educacional, a Plataforma Asta, uma tecnologia social que integra todos os conteúdos da Escola de Negócios das Artesãs, além de promover rede e facilitar o acesso ao mercado. Os 25 cursos da escola passaram a ser gerenciados em um sistema de gestão de aprendizagem (learning management system [LMS]) e um sistema de gestão de conteúdo (content management system [CMS]), sendo acessados pelos usuários cadastrados na Plataforma Asta via mobile (pelo aplicativo) ou pelo navegador. Deste modo, a organização se caracterizou como parceira fundamental para a aplicação da metodologia desta pesquisa.

\section{Resultados}

\section{Persona dos assinantes de cursos do setor de economia criativa no formato MOOC}

Na definição do Sebrae (2020c), a economia criativa é "o conjunto de negócios baseados no capital intelectual e cultural e na criatividade que gera valor econômico". 
A escolha por delimitar o campo da pesquisa para esse setor se deve ao fato de buscar uma compreensão específica do comportamento de consumo de pessoas que procuram cursos como artesanato, moda, gastronomia e afins, na modalidade EaD, para adquirirem conhecimentos em suas trajetórias pessoais, profissionais, acadêmicas ou familiares. Assim, essa primeira parte do formulário buscava mapear a persona dos assinantes de cursos em economia criativa, no formato MOOC. Antes, faz-se necessário elucidar que compreender, profundamente, o comportamento de consumo dos usuários de tais plataformas se configura como um dos primeiros aspectos a estudar durante a formatação de um plano de negócio e, também, na gestão estratégica da EaD. De acordo com Araújo (2020, p. 8): "é fundamental essa identificação, pois o produto é desenvolvido para quem irá consumir, e assim precisamos identificar onde está esse consumidor, como alcançá-lo e qual preço esse consumidor está disposto a pagar".

Pode-se compreender "produto", aqui, em sua visão mais ampla de determinada entrega que venha a satisfazer as necessidades humanas e sociais da pessoa que o busca. Tal busca pode vir carregada de signos que permeiam sua relação pessoal com o produto/ serviço no qual essa pessoa investiu, daí se falar em "percepção de valor". Parte-se do princípio de que determinado discente busca um curso na modalidade EaD por vários motivos e o modelo de negócio somado ao projeto político pedagógico do curso devem estar alinhados para corresponder a tais expectativas. Em um contexto de pensar o sistema financeiro de um curso na modalidade EaD, o resultado dessa soma pode caracterizar-se por uma "proposta de valor" que, segundo o Sebrae (2020b), seria uma espécie de "resumo do propósito da sua empresa, ou seja, o que ela pretende entregar ao mercado". Tal proposta, ao ser bem estruturada, deve direcionar-se a uma persona, que nada mais é do que um perfil geral a ser traçado do seu cliente. Em resumo, é a partir da persona criada que se consegue "delimitar características de um cliente ideal, ou seja, aquele para o qual você vai direcionar suas ações e que tem mais chances de adquirir o seu produto" (Sebrae, 2020d).

Como esperado, o público que respondeu à pesquisa era majoritariamente feminino (94\%) e obteve-se uma amostra significativamente bem distribuída entre as faixas etárias (com uma média de $25 \%$ para cada recorte geracional), com exceção da Geração Z (Centennial), de 18 a 24 anos, onde só houve 1 resposta. Optou-se pela idade de 40 anos para a persona por ser um ponto de equilíbrio, em termos de estilos de aprendizagem, comportamento e consumo, entre as diferentes gerações analisadas; $65 \%$ dos respondentes se declarou de cor branca e cerca de $74 \%$ desses indivíduos possui Ensino Superior completo, inclusive uma grande amostra com pós-graduação (43\%). O que nos leva a achados como quanto maior a escolaridade, maior o número de pessoas buscando formação contínua, corroborando a tendência de lifelong learning.

Por outro lado, os números parecem mostrar que quanto maior a classe social, menor o número de pessoas buscando formação contínua. Nesse cenário, a classe $\mathrm{C}$ se destaca 
constituindo quase metade da amostra (43\%) pesquisada e $41 \%$ das respostas são de pessoas das classes $D$ ou $E$. Estudantes ou pessoas sem fonte de renda constituem uma minoria, quase exceção (3\%), e os empreendedores predominam na amostra (54\%), sejam eles formalizados ou não, em sua grande maioria do setor de economia criativa (37\%), seguidos por artesanato (12\%) e moda (9\%). Também houve uma amostra significativa de profissionais autônomos ou liberais (43\%) ou aqueles que se declararam não empreendedores (28\%), podendo-se inferir que há um crescente interesse por parte do público em cursos no setor da economia criativa, ainda que estejam posicionados em suas carreiras. Assim, iniciamos esta pesquisa buscando compreender o perfil desse usuário para, posteriormente, montarmos uma persona e pensarmos suas motivações ao decidir investir financeiramente em determinado curso na modalidade EaD.

Após analisar todas as respostas, conclui-se que a persona mapeada no estudo é uma mulher (a quem demos o nome de Renata), tem 40 anos, é branca, pertence à classe $C$, possui Ensino Superior completo e é empreendedora da economia criativa (microempreendedora individual de uma marca de crochê). Ela tenta acessar uma grande variedade de cursos onde possa aprender novas técnicas e dicas de gestão para seu negócio, de modo que tenham valores acessíveis e sejam ofertados por instituições que passem credibilidade. Por fim, pode-se ajudá-la, conhecendo melhor seus hábitos de aprendizagem, seu comportamento de consumo para, posteriormente, formatar uma proposta de valor e de entrega dos conteúdos em uma plataforma inovadora e criativa.

Com a crescente oferta de cursos em formato MOOC somados a uma forte tendência de cada vez mais instituições oferecerem cursos livres na modalidade EaD, esse processo de inovação precisa ser o mais ágil possível. Uma das metodologias usadas nesse sentido para validar estratégias de inovação é o Lean Startup, que, como indicam Pereira e Araujo (2017, p. 268) foi adotado pela empresa Descomplica (uma das maiores plataformas de educação do país), no seguinte cenário: "tinha como propósito recolher feedbacks de primeiros usuários e analisar métricas de crescimento para aprimorar cada vez mais o seu produto". Os autores complementam que:

\footnotetext{
O referido ciclo consiste em idealizar uma nova funcionalidade ou característica para o produto (build), proveniente de feedbacks, insights das métricas analisadas ou brainstorming de sua equipe (measure) [...] Nesse caso, a equipe da Descomplica observava a reação dos usuários imediatamente após construir uma nova solução, ou seja, codificar se for uma funcionalidade do site ou a execução de uma nova característica de produto, para depois medir os resultados de aceitação dessa nova iteração (Pereira \& Araujo, 2017, p. 269).
} 
Conclui-se que conhecer a persona é importante para validar os processos de inovação e gerar estratégias que entreguem uma proposta de valor cada vez mais alinhada às expectativas e necessidades dos clientes. Após cumprir essa primeira etapa, de conhecer o público para o qual estamos desenvolvendo determinada solução educacional, fica mais fácil analisarmos sua percepção de valor ao investir financeiramente em uma plataforma.

\section{Experiência de uso das plataformas de cursos em economia criativa em MOOC}

Como sinalizado anteriormente, esta pesquisa se insere em um contexto de investimento financeiro em plataformas de cursos da economia criativa no formato MOOC. Nessa perspectiva de pensar o desenvolvimento de novos produtos e serviços educacionais, tendo por base o modelo de negócio das startups, identificou-se que se trata de um movimento recente. É nesse sentido que:

\footnotetext{
Universidades, escolas, centros de ensino, organizações empresariais, grupos de profissionais de design e hipermídia lançam-se ao desenvolvimento de portais educacionais ou cursos a distância por meio da TIC (Tecnologia da Informação e Comunicação), os quais podem suportar tanto as tradicionais formas mecanicistas de transmitir conteúdos digitalizados como processos de produção colaborativa de conhecimento (M. Medeiros \& A. Medeiros, 2018, p. 5).
}

Essa série de portais e cursos se classifica de diversas maneiras, dependendo dos respectivos modelos de negócios com focos em diferentes produtos ou serviços educacionais. $\mathrm{Na}$ revisão bibliográfica se encontram, diversas vezes, classificações diferentes para o(a) mesmo(a) aplicativo/solução educacional ou, ainda, casos de soluções educacionais que transitam por diferentes tipologias. No estudo de M. Medeiros e A. Medeiros (2018), por exemplo, foram classificadas 25 plataformas digitais e startups na área da educação, onde a plataforma Eduk está tipificada como "Plataformas e startups voltadas para alunos, professores e gestão escolar", mas também se encaixaria em "Plataformas e startups com cursos on-line voltadas para a área de negócios".

Antes de iniciarmos as análises dos resultados desta seção, faz-se necessário elucidar o conceito de MOOC, o formato de curso escolhido para a contextualização deste estudo. Tal escolha se deu pelo fato de sua tipologia ser aquela que mais se aproxima da entrega de determinada proposta de valor em uma plataforma/startup de educação. Após a revisão bibliográfica, optou-se por trabalhar com o conceito de Dal Forno e Knoll (2013, p. 6): “a sigla MOOC significa Curso On-Line Aberto Massivo (Massive Open Online Course), uma 
modalidade de ensino a distância que tem se propagado por meio de plataformas virtuais específicas espalhadas pelo mundo". Os autores complementam que:

\footnotetext{
Diferentemente dos cursos tradicionais de EaD, os MOOCs são abertos, ou seja, podem ser acessados por qualquer pessoa conectada à internet, mediante sua inscrição em uma plataforma: não há critérios para a seleção de estudantes, exceto quando é indicada a necessidade de determinado conhecimento prévio e os cursos são majoritariamente gratuitos. Por essa ampla abrangência, os MOOCs são intitulados massivos, alcançando um grande número de pessoas (Dal Forno \& Knoll, 2013, p. 6).
}

Os MOOC nem sempre são gratuitos e essa é a principal característica que permite que as plataformas e startups educacionais se apropriem de seus princípios para gerarem receitas e monetizarem suas ações. A partir do momento em que se compreende a tipologia da plataforma, consequentemente se observa quais estratégias ela tem usado para entregar sua proposta de valor ao seu usuário. É aqui que chegamos às grandes questões norteadoras deste estudo:

- Quais dores essas plataformas MOOC atendem no universo dos seus consumidores?

- De que modo elas conseguem se comunicar, operacionalizar e inovar na entrega de produtos e serviços de qualidade que atendem às expectativas do usuário?

- $\quad$ O que faz com que este se fidelize e engaje a ponto de pagar por um curso on-line que o ensine a precificar um produto artesanal, ou a fotografá-lo ou, ainda, sobre como desenvolver coleções, se existe todo um universo de conteúdos gratuitos na internet?

Foi nesse sentido, que os participantes desta pesquisa responderam 5 perguntas abertas na seção "Como tem sido sua experiência de uso da plataforma?”, que tinha como objetivo principal elucidar a experiência do usuário em sua jornada.

Os respondentes desta pesquisa assinam, em sua maioria, as plataformas Eduk (51\%), Domestika (20\%) e Udemy (18\%). Algumas das principais análises desta amostra sinalizam que $22 \%$ das pessoas assinaram ou consumiram produtos educacionais além dessas 3 principais plataformas. Trata-se de um número significativo, pois quase 1/4 dos respondentes consome outras plataformas/serviços, dentre eles cursos em plataformas independentes empreendidas por artesãs que se caracterizam como referências e se posicionam no setor. As pessoas conhecem as plataformas por meio de busca na internet (33\%) e das redes sociais (40\%), estando o Instagram e o Facebook empatados com $20 \%$ cada. Vale sinalizar que gerar engajamento e formar embaixadores é essencial para que as pessoas possam indicar os cursos em suas redes pessoais, visto que $24 \%$ dos respondentes dizem ter conhecido a plataforma por meio da indicação de amigos. Apenas $1 \%$ sinalizou 
tê-la conhecido em um ambiente fora do digital: na feira Mega Artesanal. Pode ser um viés para discorrer sobre a necessidade de mindset digital das feiras, em uma integração de estratégias multicanais.

A primeira pergunta aberta era "O que mais te chamou atenção nesta plataforma?" - os respondentes sinalizaram interesse em plataformas com uma grande variedade, diversidade e quantidade de cursos oferecidos. Em um segundo momento foi citada a busca por conhecimento, creditado por profissionais reconhecidos no mercado. Na segunda pergunta, a amostra respondeu que o que mais gosta nessa plataforma, mais uma vez indo além da diversidade e variedade, é sua facilidade de acesso aliada às possibilidades de aprendizado e conhecimento. Destaca-se a experiência visual, associada a um bom design em todas as etapas (desde a navegação na plataforma até o material didático).

As principais necessidades que essa plataforma atende permeiam a busca por conhecimento e aprendizado, principalmente na melhoria de suas técnicas, onde as palavras "aprimorar" e "aperfeiçoamento" assumiram destaque. Percebe-se que tal combinação de necessidades difere quanto à diversidade de expectativas, dependendo de com qual plataforma o usuário se relaciona. Por exemplo: Eduk, Domestik e Udemy têm, claramente, diferentes propostas de valores e um mesmo usuário assinante as busca por motivos diversos, pois também são diversas as suas expectativas e necessidades, conforme o relato a seguir da respondente Raphaela Procópio, de 30 anos:

\begin{abstract}
[A qual tipo de necessidade sua ela (a plataforma) atende?]
Conhecimentos aleatórios. Eu adoro fazer cursos, aprender coisas novas e no momento que me inscrevi estava interessada em algum tema específico para o meu dia-a-dia ou alguma temática especifica. Por exemplo, na Udemy foram conteúdos voltados para negócios, já na Eduk de artesanatos. Tenho interesse no de aquarela da Domestika, mas ainda não me inscrevi. O valor e o formato on-line facilitam o investimento.
\end{abstract}

Esse tipo de relato reforça a importância da gestão de negócios em educação sob o viés da gestão estratégica, quando nos deparamos com diferentes possibilidades de comportamento e consumo, em um mesmo usuário que pode, inclusive, vir a assinar diferentes plataformas, simultaneamente. É essencial compreender as diversas motivações desse consumidor e suas diferentes formas de apreender conhecimento, quando ele descreve que "a Udemy é profissional e a Domestika é hobby", como sinalizado por Ghavami, de 35 anos, empreendedora da economia criativa. 
Os respondentes relataram que, de modo geral, o que menos gostam nas plataformas são as questões que envolvem a qualidade dos cursos em longo prazo. Isso se reflete desde as mudanças nas formas de cobrança até o nivelamento dos conteúdos em uma trilha que seja desafiadora e faça sentido permanentemente. De certo modo, esse usuário parece precisar ser motivado ao longo do processo, com estratégias que promovam seu engajamento não só na aquisição de conhecimento e acesso ao curso, mas nas motivações maiores para continuarem acessando essa determinada plataforma. Para tanto, a qualidade dos cursos e conteúdos, em longo prazo (e não somente no momento da captação/ estratégias de marketing) são essenciais.

Por fim, alguns aspectos que frustram ou que poderiam sofrer alterações para melhorar a experiência do usuário passam por temas que, de modo geral, envolvem aspectos da integração on-line $\times$ offline nos recursos que essas plataformas oferecem, como, por exemplo: possibilidade de baixar o vídeo da aula para assistir posteriormente (quando estiver sem internet, como o Netflix, por exemplo), campos para anotações, vitrines para exposições dos produtos, conteúdos que abordem as questões gerenciais dos negócios e não somente o aspecto criativo, dentre outros. Toda essa integração precisa vir com um storytelling muito bem definido na etapa do designer instrucional, pois mesmo que se pense a continuidade de determinado curso, ainda que nivelado corretamente, o mais importante é que ele converse com toda as funcionalidades da plataforma, em uma espécie de "gamificação" da experiência de aprendizagem.

Como se introduziu neste estudo, é a partir de uma boa gestão estratégica da EaD que se alcança excelência em projetos educacionais, em seus diferentes modelos. Foi nesse sentido que se discutiram brevemente nesta seção as diferentes tipologias de startups e plataformas digitais educacionais, onde se priorizou, para este estudo, o modelo dos MOOC que geram receitas para novos negócios no formato de startups, considerando as peculiaridades desse modelo de negócio. Essa receita advém de diferentes formatos, dependendo da estratégia da startup, mas tendo em comum o profundo conhecimento acerca da experiência de uso da plataforma por parte do usuário para seu consequente investimento financeiro na aquisição de conhecimento.

\section{Experiência de aprendizagem nas plataformas de cursos em economia criativa}

Esta seção investiga como se deu a experiência de aprendizagem dos usuários nas plataformas MOOC que assinaram; $67 \%$ deles investiram em cursos de artesanato, seguidos por design, moda e publicidade/marketing (empatados com 18\% cada), audiovisual (13\%) e gastronomia (10\%). Após a análise dos nomes dos cursos, percebe-se que apenas 3\% 
abordavam algum assunto sobre gestão, $9 \%$ sobre vendas e todos os demais contemplavam aspectos técnicos, com foco na melhoria das habilidades criativas dos assinantes. Quem faz determinado curso que não seja de técnica pode ser considerado exceção, pois apenas $12 \%$ da amostra fez algum curso voltado ao desenvolvimento do negócio. Isso demonstra que o processo de aquisição do conhecimento é associado a um hobby, sem necessariamente complementar uma formação superior ou ter uma aplicação prática nos negócios.

Sobre o tipo de investimento realizado, 39\% se deram a partir de assinatura de plano, 37\% pagaram por um curso individual e 14\% realizaram o curso gratuito e pagaram somente pela certificação. É importante ressaltar a estratégia do vale presente, na qual 3\% compraram algum curso para si, $1 \%$ ganhou e $1 \%$ comprou para dar de presente a alguém. Ou seja, $5 \%$ é um número expressivo para pensar os modos de aquisição de conhecimento como algo passível de ser presenteado, funcionando como uma economia do afeto. Esses dados sobre o tipo de investimento podem sugerir dicas para pensar também os tipos de aprendizagem: há quem prefira pagar por uma assinatura e ter acesso a uma trilha completa e guiada de cursos (e possivelmente com vários outros elementos de acompanhamento dessa aprendizagem como tutorias, network, mentorias etc.); há quem fique satisfeito com um curso individual para aprender algo pontualmente, de modo objetivo, e há quem não pague para ter acesso ao conhecimento, mas sim pela certificação de que a sua aprendizagem foi conclusiva.

Mais da metade da amostra (58\%) investe, no máximo, até $\mathrm{R} \$ 100,00$ e $31 \%$ das pessoas investem entre $R \$ 101,00$ e $R \$ 300,00$. Apenas $11 \%$ da amostra investem mais de $\mathrm{R} \$ 301,00$ em determinado curso. Os principais motivos ao optar por fazer o investimento nessa determinada plataforma e não em outra perpassam a dupla credibilidade e marketing. E é nesse aspecto que, mais uma vez, reforça-se a importância de mensurar a experiência da aprendizagem: quanto mais credibilidade tem a instituição promotora do curso, mais o aluno confia em sua grade e suas metodologias de ensino, pois se pressupõe uma confiança plena nos profissionais envolvidos no desenvolvimento e repasse do conteúdo. Várias verbalizações surgiram reforçando esse motivo como decisivo para fazer o investimento, seja pela necessidade da certificação com uma plataforma que fosse conhecida, seja porque na pesquisa pareceu ser aquela de maior credibilidade ou, ainda, porque os cursos eram elaborados por artistas nos quais as pessoas confiavam.

Existe uma linha muito tênue entre a credibilidade da instituição promotora e suas estratégias de marketing. Ao passo que a divulgação dos cursos e suas estratégias de encantamento são importantes, o consumidor também está atento se tais táticas de marketing contemplam o mais importante, que é o compromisso com um conteúdo de qualidade que promova uma aprendizagem plena. Desse modo, não basta somente convidar o Ronaldo Fraga para dar determinado curso de moda, ele precisa, de fato, passar conhecimento naquele curso pelo qual o assinante investiu, de modo que este aprenda 
com rapidez e eficiência. Assim, a credibilidade da instituição (escola ter um nome muito forte no mercado onde atua) associada à estratégia de marketing (convidar um estilista renomado) promovem uma experiência de aprendizagem agradável que, logo, são fatores importantes para se optar por investir financeiramente no curso.

Ao passo que credibilidade e marketing são importantes, existem alguns itens que são decisivos para que se pague por determinado curso. A Tabela 1 apresenta um ranking dos 8 itens previamente apresentados aos respondentes, tendo como critério principal o maior número de votos sucessivamente nos itens "mais", "muito", "indiferente", "pouco" e "menos" importante.

Tabela 1 - Ranking de importância dos itens decisivos para o aluno investir financeiramente

\begin{tabular}{|l|l|l|l|l|l|l|l|}
\hline$\#$ & \multicolumn{2}{|c|}{ Item } & Menos & \multicolumn{1}{c|}{ Pouco } & Indiferente & Muito & Mais \\
\hline 1 & Aprender novas habilidades & 1 & 5 & 3 & 31 & 60 \\
\hline 2 & Grande quantidade de cursos e tutoriais & 13 & 11 & 10 & 30 & 36 \\
\hline 3 & & & & & \\
\hline 4 & Prepara-se para nova carreira & 13 & 11 & 21 & 24 & 31 \\
\hline 5 & Acesso à rede de networking & 11 & 5 & 13 & 40 & 31 \\
\hline 6 & Programação ao vivo exclusiva & 12 & 13 & 21 & 27 & 27 \\
\hline 7 & Novos cursos semanais & 19 & 13 & 26 & 24 & 18 \\
\hline 8 & Ganhar certificado ou diploma & 19 & 12 & 26 & 29 & 14 \\
\hline
\end{tabular}

Fonte: Elaborada pelos autores.

Percebe-se que dentre os itens mais decisivos para o aluno investir em um curso em economia criativa em plataformas MOOC estão: aprender novas habilidades, acessar uma grande quantidade de cursos e tutoriais e, empatados, preparar-se para uma nova carreira e ter apostilas e moldes. Esses dados denotam que a experiência da aprendizagem é um item de suma importância, acentuado pela diferença do número de votações em relação ao único quesito que tinha o termo "aprender" em sua composição. Nenhuma outra categoria teve uma votação tão expressiva e pode-se afirmar que mesmo em cursos com características fortemente guiadas para a aplicação no mercado, o processo de aprendizagem é o mais decisivo para a escolha desse aluno.

Em uma faixa de transição, percebe-se que ter acesso a apostilas e moldes é um item muito importante e que também contempla a experiência de aprendizagem. Vários foram os relatos de usuários elogiando plataformas que tenham essas iniciativas ou contando que a ausência desse item os frustrou em algum momento. Com um resultado mais equilibrado surgiu o acesso à rede de networking, com maior inclinação para ser muito ou mais importante, no entanto, com votações mais distribuídas. Infere-se que é o tipo de inovação 
que pode fidelizar os usuários, mas, também, reforçar suas maneiras de aprender, de modo mais ativo, ao realizar trocas entre pares com interesses comuns. O networking pode ser uma excelente ferramenta para potencializar as ecologias de aprendizagem e formação de redes no processo educativo, pois,

[...] esta forma de pensar o processo educativo enquadra-se numa estratégia de viver a educação enquanto espaço aberto, flexível e híbrido e em compreender o processo de ensinar e de aprender enquanto um sistema vivo, que se constrói, adapta e transforma de acordo com as necessidades de todos os seus intervenientes (Dias-Trindade, 2020, p. 4).

Finalmente, nos últimos 3 lugares do ranking estão empatados programação ao vivo exclusiva, novos cursos semanais e ganhar um certificado ou diploma. Apesar de haver certo equilíbrio de votos com os demais critérios, existe uma indiferença expressiva em relação às estratégias de aulas ao vivo e da quantidade de cursos inéditos. Um número expressivo acha muito importante, mas um ponto de contato entre os indiferentes e estes é que ambos concordam que tais ações parecem pouco planejadas ou eficientes diante do processo de aprendizagem. São interessantes, entregam certos elementos do marketing, mas não necessariamente ajudam a aprender melhor. Por fim, um ponto de maior atenção desse ranking é a entrega na proposta de valor associado a um certificado ou diploma. Parece haver uma mudança de paradigma em relação ao peso ou à aplicação prática desses documentos onde, apesar de procurar instituições com credibilidade para aprender algo, para mais da metade de amostra um certificado parece ser indiferente, pouco ou menos importante.

A última questão desta seção abordava uma escala similar à anteriormente apresentada, desta vez em relação a 4 sentenças que tinham por objetivo aferir a percepção do retorno do valor investido no curso em diferentes áreas da vida do aluno: acadêmica, familiar, profissional ou pessoal. Os critérios adotados foram do "menos" ao "mais" verdadeiro e do mesmo modo que na questão anterior, estruturou-se um ranking para avaliar cada um dos itens votados (Tabela 2). 
Tabela 2 - Ranking de percepção do retorno do valor investido em diferentes áreas da vida

\begin{tabular}{|l|l|l|l|l|l|l|}
\hline$\#$ & $\begin{array}{c}\text { Percebo que o valor investido teve } \\
\text { retorno na minha vida }\end{array}$ & Menos & Pouco & Indiferente & Muito & Mais \\
\hline 1 & Profissional & 7 & 10 & 10 & 39 & 34 \\
\hline 2 & Pessoal & 7 & 8 & 12 & 40 & 33 \\
\hline 3 & Acadêmica & 17 & 17 & 26 & 24 & 16 \\
\hline 4 & Familiar & 19 & 10 & 36 & 20 & 15 \\
\hline
\end{tabular}

Fonte: Elaborada pelos autores.

Percebe-se que está classificada como "mais verdadeira" a percepção do valor investido nos cursos retornando para a vida profissional, seguida pela pessoal, mais do que na vida acadêmica e, por fim, na familiar. A experiência do aprendizado com a plataforma foi direcionada a uma aplicação prática na vida profissional e talvez isso explique alguns itens anteriormente apresentados, como o baixo interesse por certificados ou o grande número de empreendedores nos perfis mapeados. Mas o aspecto do retorno pessoal ganha relevância principalmente porque corrobora a teoria de que as pessoas acessam a tais cursos na economia criativa buscando um hobby, além de aprimorar uma técnica, e isso gera estratégias de entrega de experiências de aprendizagem totalmente diferentes. No eixo acadêmico, percebe-se que houve maior equilíbrio de percepções onde esses cursos acessados não necessariamente complementam alguma formação. E, por fim, o resultado do eixo familiar, que é uma área mais sensível à medição de impacto, mas igualmente importante de mapear, denota que esse eixo pode ser mais bem explorado, visto que a grande maioria respondeu "indiferente" ao invés de "pouco" ou "menos" verdadeiro em relação à percepção do retorno do valor investido.

Todos esses dados coletados reforçam a abordagem de Rumble (2003 como citado em Mill \& Monteiro, 2020, p. 23) ao elucidar "uma longa lista de ações típicas do gestor pedagógico, agrupando-as em seis categorias: elaboração de cursos, produção dos cursos, ofertas dos cursos, recrutamento dos alunos, serviços de apoio e acompanhamento dos estudantes e análise de mercado". Como o autor detalha, é de suma importância que o gestor pedagógico da EaD esteja sincronizado com os métodos traçados pelo gestor estratégico de determinada plataforma e o mesmo raciocínio se aplica a diferentes modelos de negócio educacionais. Isso porque, mesmo em uma startup, essas 6 categorias apresentadas precisam complementar-se mutuamente em um processo ágil que, como já se detalhou neste estudo, estão presentes nos ciclos apresentados anteriormente: mapeamento da persona, percepção de sua experiência de uso da plataforma e experiência de aprendizagem. Desse modo, desde o pensar a elaboração de um curso, produzi-lo e ofertá-lo, até recrutar os alunos, acompanhando-os até a constante análise do mercado, 
são processos que validam hipóteses e criam ambiências de inovação. São ciclos como esses que permitem que cursos de maior qualidade sejam criados, de modo a oferecer 0 produto certo à persona mapeada, potencializando sua aprendizagem em uma plataforma cada vez mais personalizada.

\section{Conclusão}

A partir do momento em que se conhece, profundamente, seu cliente, com suas necessidades, dores e expectativas, o portfólio de produtos e serviços pode ser adaptado em um curva constante de aprendizado e feedback. No caso de uma startup, esse processo precisa ser o mais ágil possível, de modo que a empresa consiga ganhar fôlego e escala para gerar resultados, entregando qualidade ao seu cliente e atraindo a atenção de possíveis investidores. Segundo Piva e Leandro (2010, p. 9), "a visão clássica em investimentos teme pela irreversibilidade de ativos. Os investimentos em EaD oferecem uma flexibilidade elevada por meio da visão da construção de plataformas de conhecimento". Quando startups e plataformas educacionais como Descomplica, Geek e Veduca, por exemplo, conseguem crescer ao ponto de tornarem-se cases ou até serem incorporadas às políticas públicas, isso demonstra o poder da gestão estratégica da EaD.

Este estudo buscou demonstrar que conhecer o usuário/cliente/aluno de determinada plataforma educacional é essencial para promover inovações constantes em seus processos e suas propostas de valor. A Figura 1 apresenta o Mapa de Empatia, que resume os principais pontos desta pesquisa. 
Figura 1. Mapa de empatia.

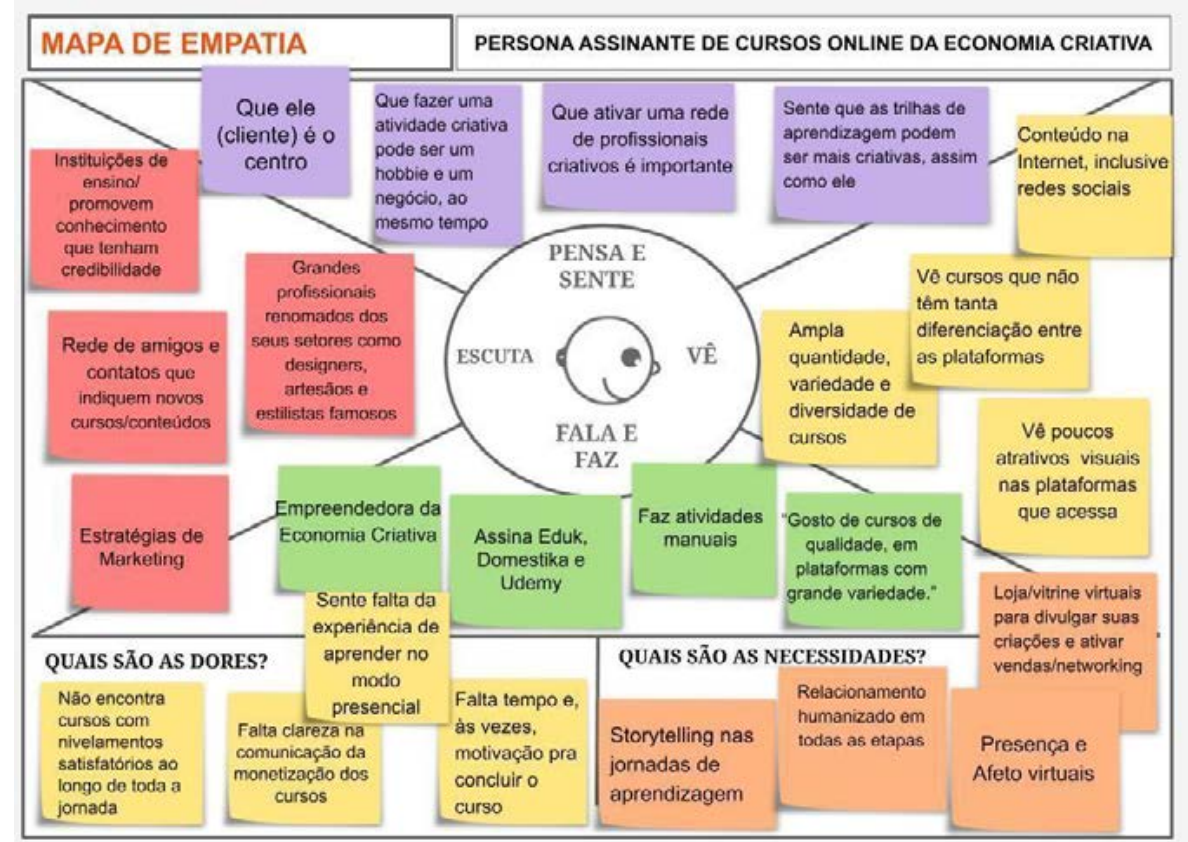

Fonte: Elaborada pelos autores.

O Mapa de Empatia enquanto canvas de compilação dos resultados foi adotado na conclusão deste estudo por constituir uma ferramenta visual de fácil assimilação e por sua capacidade de integração dos principais tópicos levantados. Desse modo, sugere-se o uso da ferramenta em estudos que tenham propostas similares e, dependendo do caso, ela pode ser impressa, com vistas a facilitar uma sessão de brainstorming entre o(a) gestor(a) estratégico(a) e sua equipe, presencialmente. No entanto, também é possível adaptar a ferramenta a diversas possibilidades de templates hospedados nos modelos digitais, para facilitação de equipes remotas por meio de videoconferências.

Longe de resumir-se a post-its, neste estudo, a inovação (mais do que uma sugestão ou recomendação) surge como premissa básica para o setor de educação, em suas mais diversas ramificações, sejam mais tradicionais ou contemporâneas. Sousa (2012) alerta para a importância de promover ambiências inovadoras em processos de gestão em sistemas de EaD, de modo que o usuário perceba a efetividade dessa inovação em sua experiência de aprendizagem. $\mathrm{O}$ autor complementa que

[...] a capacidade de produzir, interpretar, articular e disseminar conhecimentos passa a ocupar espaço privilegiado na agenda estratégica dos governos e das organizações em geral, de modo que reconhecem como cada vez mais cruciais: a formação dos cidadãos, a qualidade dos conhecimentos que são capazes de 
produzir e transferir para os sistemas produtivos, e a capacidade de geração de conhecimentos e tecnologias na produção de bens e serviços (Sousa, 2012, p. 91).

De modo similar ao do autor, o que se buscou neste estudo foi captar pontos de melhorias ao investigar a percepção de valor dos assinantes de cursos on-line no setor de economia criativa. Entendendo que cada vez mais as organizações em geral (e não somente as instituições de ensino) passam a oferecer à sociedade diferentes modelos de negócios que entregam diferentes propostas de valor, espera-se que o desdobramento deste estudo contribua para a inovação a partir da ressignificação da gestão do conhecimento em produtos e serviços educacionais que, de fato, sanem as dores e atendam às necessidades de seus mais diversos discentes.

Em um cenário de intensa revolução nos modos de pensar e fazer educação, de ressignificação de vários setores e instituições, a EaD tem uma oportunidade única de entregar diversas experiências que promovam a conexão, a presença, o aprendizado cada vez mais ativo e criativo. E, decerto, conhecer profundamente o(a) persona/aluno/usuário para entregar uma proposta de valor cada vez mais alinhada aos seus propósitos (e do mundo) é um primeiro passo essencial para a ressignificação dos modos de ensinar e aprender a distância.

\section{Referências bibliográficas}

Araújo, A. (2020). Gestão de negócios em educação e tecnologias. São Carlos, SP: Pixel.

Dal Forno, J. P., \& Knoll, G. F. (2013). Os MOOCS no mundo: um levantamento de cursos online abertos massivos. Nuances: Estudos sobre Educação, 24(3), 178-194.

Dias-Trindade, S. (2020). Ecologia de aprendizagem e redes virtuais. São Carlos, SP: Pixel.

Domingues, A. A., Floyd-Wheeler, K., \& Nascimento, N. S. (2017). Empreendedorismo digital: um estudo sobre o uso da tecnologia como geração de negócios nas startups educacionais. Universitas: Gestão e TI, 7(1-2), 171-175.

Limeira, T. (2018). Negócios de impacto social. São Paulo, SP: Saraiva.

Medeiros, M., \& Medeiros, A. (2018). Educação e tecnologia: explorando o universo das plataformas digitais e startups na área da educação. In Anais do 50 Congresso Nacional de Educação. João Pessoa, PB.

Mill, D. (2017). Gestão estratégica da educação a distância. São Carlos, SP: Pixel.

Mill, D., \& Monteiro, M. I. (2020). Gestão pedagógica em educação a distância. São Carlos, SP: Pixel. Pereira, R. C., \& Araujo, F. O. (2017). Complica ou descomplica? Reflexões sobre decisões de fazer ou comprar na maior startup brasileira de educação. Revista Eletrônica de Administração, 23(3), 259-287. 
Piva, D., Jr., \& Leandro, C. R. (2010). O retorno do investimento na educação a distância. In Anais do Simpósio Brasileiro de Informática na Educação. Indaiatuba, SP..

Serviço Brasileiro de Apoio às Micro e Pequenas Empresas. (2020a). Conheça o Mapa de Empatia. Recuperado de https://inovacaosebraeminas.com.br/conheca-o-mapa-da-empatia/

Serviço Brasileiro de Apoio às Micro e Pequenas Empresas. (2020b). Manual de instruções: 6 modelos de canvas. Recuperado de http://materiais.inovacaosebraeminas.com.br/kit-canvas

Serviço Brasileiro de Apoio às Micro e Pequenas Empresas. (2020c). O que é economia criativa.

Recuperado de https://www.sebrae.com.br/sites/PortalSebrae/segmentos/economia_ criativa/como-o-sebrae-atua-no-segmento-de-economia-criativa,47e0523726a3c510Vgn VCM1000004c00210aRCRD

Serviço Brasileiro de Apoio às Micro e Pequenas Empresas. (2020d). O que é persona e como criar uma que fortalece sua estratégia de negócio. Recuperado de https://inovacaosebraeminas.com.br/o-que-e-persona-e-como-criar-uma-fortalece-sua-estrategia-de-negocio/

Sousa, J. C. (2012). Processo de inovação na gestão de sistemas de educação a distância: estudo de casos na Universidade de Brasília e Universidade Aberta de Portugal (Tese de Doutorado).

Universidade de Brasília, Brasília, DF.

\section{Para citar este artigo}

\section{Norma A - ABNT}

OLIVEIRA, F. A.; MILL, D. Percepção de valor de assinantes de cursos on-line em economia criativa. Conhecer: Debate entre o Público e o Privado, v. 11, n. 27, p. 150-170, 2021.

\section{Norma B - APA}

Oliveira, F. A., \& Mill, D. (2021). Percepção de valor de assinantes de cursos on-line em economia criativa. Conhecer: Debate entre o Público e o Privado, 11(27), 150-170.

\section{Norma C - Vancouver}

Oliveira FA, Mill D. Percepção de valor de assinantes de cursos on-line em economia criativa. Conhecer: Debate entre o Público e o Privado [Internet]. 2021 [cited Ago 21, 2021];11(27):150-170. Available from: https://revistas.uece.br/index.php/revistaconhecer/article/view/7156 